\title{
Perception of Indian Dental Students to Pursue Higher Education Abroad during COVID-19
}

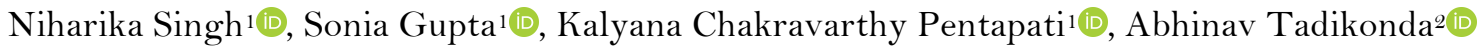

${ }^{1}$ Department of Public Health Dentistry, Manipal College of Dental Sciences, Manipal, Manipal Academy of Higher Education, Manipal, Karnataka, India.

${ }^{2}$ Department of Public Health Dentistry, Sri Sai College of Dental Surgery, Vikarabad, Telangana, India.

Correspondence: Dr. P. Kalyana Chakravarthy, Department of Public Health Dentistry, Manipal College of Dental Sciences, Manipal, Manipal Academy of Higher Education, Manipal, Karnataka, India. E-mail: drkalyan81@gmail.com

Academic Editor: Alessandro Leite Cavalcanti

Received: 23 December 2020 / Review: 30 January 2021 / Accepted: 08 February 2021

How to cite: Singh N, Gupta S, Pentapati KC, Tadikonda A. Perception of Indian dental students to pursue higher
education abroad during COVID-19. Pesqui Bras Odontopediatria Clín Integr. 2021; $21: e 0265$.
https://doi.org/10.1590/pboci.2021.096

\begin{abstract}
Objective: To evaluate Indian dental students' perception of seeking international dental higher education during COVID-19. Material and Methods: We conducted an online survey among the dental students. A self-administered questionnaire was prepared, which had information on country choice, reasons for the decision to study abroad, measures to be taken by the foreign universities because of COVID-19, the application's status, current plan, and opinions on exploring other possibilities. Results: Four hundred students constituted the final sample, out of which the majority were females (69.3\%). Most of the students were not sure about their status in the application process (63\%). The current plan to study abroad remained uncertain for almost half of the students (50.2\%). Concerning the status of the application process, a significantly higher number of female students were "not sure" and are still "searching colleges" ( $<<0.001)$. Similarly, a higher number of females were "uncertain" or "postponed" or "canceled" when compared to the males concerning the current plan to study abroad $(\mathrm{p}=0.001)$. Also, a significantly higher proportion of female students cited the study budget as the main deterrent for pursuing a career abroad and opined that "flexible study options" will help them get admissions post-COVID-19 ( $\mathrm{p}=0.001$ and 0.035). Conclusion: A substantial impact was perceived by Indian dental students concerning higher education abroad, more among females.
\end{abstract}

Keywords: COVID-19; Education, Dental, Graduate; Self Concept. 


\section{Introduction}

Choosing a career is one of the critical and impactful decisions in a student's life. Advances in dental research, with opportunities to treat patients, make dentistry an inspiring and enriching profession. It is both demanding and remunerative, thus has the potential to attract new aspirants. It takes years of dedicated training and expertise to get a bachelor's degree in dentistry. The current situation of Indian dental graduates has a lot of struggle in building up the career. India has 269 institutes offering MDS and 313 offering BDS [1], producing about 24000 graduates every year [2]. There has been a marked improvement in the dentist-topopulation ratio in India (1:5000) [3].

There are diverse options available for graduated dentists to pursue a higher qualification in their chosen field of specialization elsewhere. The factors that influence the choice of profession relates to the expectations of the work [4]. The majority of dental students prefer to pursue specialty degrees [5]. Popular reasons for choosing dentistry from earlier studies were family advice, prestige, and medical sciences interest [6]. After graduation, $35.1 \%$ planned to do post-graduation in India, while $13.5 \%$ planned to pursue postgraduation abroad. Fewer students were interested in pursuing a research-based career. The majority of the students planned to pursue a post-graduation degree after completing graduation, and few were inclined to be employed in the public or private sector.

Dental students perceive future career challenges during graduation [7]. Concern about future career challenges during graduation is a global issue. The increasing number of dental schools in India and a rising number of graduating dentists are few causes of stress. It owes to quality dental education deficiencies with unrealistic criteria for getting accepted into premier institutes for higher education, lean and insufficient job opportunities [8].

Another option for Indian dental graduates is pursuing higher education abroad. An excessive number of students are now exhibiting a desire to pursue their further studies or career abroad in response to various factors, including monetary benefits, a better quality of life, a better job and research opportunities, and an unparalleled experience living overseas [6]. Trends in international student flows suggest that non-European students in the last decade were more in European countries, and a significant number of students are from India [9].

COVID-19 has involved 216 countries and has become a global public health problem [10]. The spread of COVID-19 disease may have an unequaled and potential effect on dental students with high uncertainty regarding their future and foreign dental education [11]. The economic, travel and market uncertainty caused by the COVID-19 pandemic may also have a telling effect on the aspirants. Most dental clinics were closed indefinitely or provided emergency services that could further deter aspirants from seeking foreign education due to the profession's faint prospects [12]. A Recent review has discussed numerous challenges that would be encountered in dental practice during and post-COVID-19 [13]. A recent study on various dental schools from different countries highlighted the many difficulties that have been met by individuals, communities, and dental schools. Students faced disruption in the dental education and clinical training, and faculties in the dental schools have experienced various hardships [14]. Many essential aspects like the need to re-evaluate the policies and curriculum, distance learning, outreach, and multi-professional support have been identified as the gaps in the US dental school preparedness for pandemics [15]. Studies reported the impact of COVID-19 on dental and medical education [16,17]. In contrast, no studies have reported the effect or perceptions of dental students' on pursuing international dental higher education during COVID-19. Given this background, we aimed to evaluate Indian dental students' perceptions of international 
dental higher education during COVID-19 and compare these characteristics between male and female dental students.

\section{Material and Methods}

Study Design and Ethical Clearance

We conducted a cross-sectional online survey among the final-year students, interns, and recent dental graduates. Permission to conduct the study was obtained from the institutional ethics committee of the Kasturba Hospital and Kasturba Medical College, Manipal (IEC: 343/2020). We have registered the protocol with the clinical trial registry of India (CTRI/2020/07/026473). Informed consent was obtained from all the participants.

Sample and Data Collection

A response distribution of $50 \%, 5 \%$ margin of error, and $95 \%$ confidence interval yielded a sample size of 377 . We had collected data related to age, sex, and a screening question to evaluate their plan on pursuing higher education abroad. A self-administered questionnaire was prepared, which had information on country choice for higher education, reasons for studying abroad before COVID-19, views on studying abroad after COVID-19, and opinions on the measures taken by the foreign universities to facilitate international students. Students could choose more than one option for these questions. The questionnaire also included information on their application process status, current plan because of COVID-19, and opinions on exploring other possibilities.

The questionnaire was prepared based on the panel's inputs (dental student representatives and faculty members) received over three rounds and were adapted to the contexts of Indian dental education and COVID-19. A pilot study was conducted to evaluate the feasibility of the questionnaire, face and content validity. The questionnaire received favorable feedback and required minor edits in wording to maintain clarity. An online survey tool using Google forms was made, and the investigators shared the link to the survey with a brief explanation about the need for the study through WhatsApp study groups. Students were encouraged to fill in the questionnaire and were requested to share the same with their peers. We invited approximately 4000 students from 30 government and private dental schools to participate in this study. Due to this study's nature, the investigators had no role in the participant selection as the survey tool was circulated through the study groups among these institutions' student groups. The survey was kept open for receiving responses from 17th May 2020 to 6th September 2020. Dental students who were not planning to pursue higher education abroad or were not willing to participate were excluded.

\section{Data Analysis}

All the analysis was done using SPSS version 20. The results were presented as descriptive statistics, and the Chi-square test was used to evaluate the differences between males and females. A p-value of $<0.05$ was considered statistically significant. Construct validity was assessed with the variables that evaluated the "reasons that have led to the decision to study or to appear for licensing exams overseas before Covid-19" and "cons of pursuing your career abroad after COVID-19 pandemic" among students who were not sure and those who have applied, or searching colleges. Internal consistency of the questionnaire was performed using Kuder Richardson 21 test (KR-21) for all the 14 items of the two domains "reasons that have led to the decision to study or to appear for licensing exams overseas before COVID-19" and "cons of pursuing your career abroad after COVID-19 pandemic" and within the domain level. 


\section{Results}

A total of 535 students responded, out of which 12 students declined to participate. Out of these, 123 students were further excluded as they had no intention to pursue higher education abroad. Four hundred students constituted the final sample, out of which the majority were females (69.3\%) and currently pursuing final year dentistry (62.3\%). The mean age of the students was 22.48 ( $\mathrm{SD}=1.47)$. There was no significant difference in the distribution of students with $(n=400)$ or without $(n=123)$ plan of studying abroad between males and females $(\mathrm{p}=0.841)$.

Most of the students were not sure about their status in the application process (63\%). The current plan to study abroad remained uncertain for almost half of the students $(50.2 \%)$, while nearly $1 / 4^{\text {th }}$ of the students would like to postpone their plans due to the COVID pandemic. If conditions are not conducive, more than $3 / 4^{\text {th }}$ of the students would consider taking a year break and explore other possibilities. Concerning the status of the application process, a significantly higher number of female students were "not sure" and are still "searching colleges" when compared to male students $(\mathrm{p}<0.001)$. Similarly, concerning the current plan to study abroad, a significant number of female students were "uncertain" or "postponed" or "canceled" when compared to the male students $(\mathrm{p}=0.001)$ (Table 1$)$.

Table 1. Distribution and comparison of the perceptions in pursuing higher education abroad between male and female dental students.

\begin{tabular}{|c|c|c|c|c|c|}
\hline Questions & Male & Female & $\begin{array}{l}\text { Total } \\
\mathrm{N}(\%)\end{array}$ & p-value & Power \\
\hline \multicolumn{6}{|c|}{ What is the status of your application process? } \\
\hline Enrolled & 5 & 5 & $10(2.5)$ & $<0.001$ & 100 \\
\hline Filling out applications & 12 & 6 & $18(4.5)$ & & \\
\hline Not sure & 59 & 193 & $252(63.0)$ & & \\
\hline Searching for colleges & 47 & 73 & $120(30.0)$ & & \\
\hline \multicolumn{6}{|c|}{$\begin{array}{l}\text { Considering the COVID }-19 \text { pandemic, what is your current plan } \\
\text { to study overseas? }\end{array}$} \\
\hline Cancelled & 6 & 22 & $28(7.0)$ & 0.002 & 100 \\
\hline Postponed & 27 & 66 & $93(23.2)$ & & \\
\hline Uncertain & 52 & 149 & $201(50.2)$ & & \\
\hline Unchanged & 38 & 40 & $78(19.5)$ & & \\
\hline \multicolumn{6}{|c|}{$\begin{array}{l}\text { If conditions are not conducive to study abroad, would you be } \\
\text { willing to take a break for one year and consider exploring other } \\
\text { possibilities? }\end{array}$} \\
\hline Maybe & 37 & 136 & $173(43.2)$ & $<0.001$ & 100 \\
\hline No & 42 & 50 & $92(23.0)$ & & \\
\hline Yes & 44 & 91 & $135(33.8)$ & & \\
\hline
\end{tabular}

The most sought-after countries for pursuing higher education were the US (72.5\%), UK (68\%), and Australia and New Zealand (63.7\%). The most common reasons for pursuing higher education abroad were "Better quality of education and training," "Better lifestyle and living standards," "Ease in finding work after education," "Better research opportunities," and "Desire to live and work abroad." The most critical disadvantage perceived to study abroad after COVID-19 pandemic was "difficult to obtain permanent residency," "travel restrictions," "tougher admission protocol," and "study budget." Most of the students opined that universities should "Ease in visa formalities," "Flexible admission criteria," and "Flexible study options" (Table 2). 
Table 2. Distribution and comparison of the preferences and opinions in pursuing higher education abroad between male and female dental students.

\begin{tabular}{|c|c|c|c|c|c|}
\hline Questions & Male & Female & $\begin{array}{l}\text { Total } \\
\text { N }(\%)\end{array}$ & p-value & Power \\
\hline \multicolumn{6}{|l|}{$\begin{array}{l}\text { Which countries are you considering to study in or appear for } \\
\text { licensing exams? }{ }^{\dagger}\end{array}$} \\
\hline USA & 89 & 201 & $290(72.5)$ & 0.97 & 5 \\
\hline UK & 86 & 186 & $272(68)$ & 0.58 & 20 \\
\hline Europe & 68 & 126 & $194(48.5)$ & 0.07 & 97 \\
\hline ANZ & 71 & 184 & $255(63.7)$ & 0.09 & 96 \\
\hline Middle east & 43 & 83 & $126(31.5)$ & 0.32 & 59 \\
\hline South Asian Countries & 22 & 62 & $84(21)$ & 0.31 & 58 \\
\hline \multicolumn{6}{|l|}{$\begin{array}{l}\text { Which of the following reasons have led to your decision to study } \\
\text { or to appear for licensing exams overseas before COVID-19 } \\
\text { surfaced? }{ }^{+}\end{array}$} \\
\hline Better quality of education and training & 103 & 243 & $346(86.5)$ & 0.28 & 68 \\
\hline Ease in finding work after education & 92 & 217 & $309(77.2)$ & 0.44 & 40 \\
\hline Increasing competition in India & 92 & 147 & $239(59.8)$ & $<0.001$ & 100 \\
\hline Desire to live and work abroad & 89 & 205 & $294(73.5)$ & 0.73 & 12 \\
\hline Better research opportunities & 95 & 220 & $315(78.8)$ & 0.62 & 19 \\
\hline Unavailability of certain courses in your college/country & 60 & 122 & $182(45.5)$ & 0.38 & 48 \\
\hline Better lifestyle and living standards & 104 & 223 & $327(81.8)$ & 0.34 & 64 \\
\hline \multicolumn{6}{|l|}{$\begin{array}{l}\text { According to you, what are the cons of pursuing your career abroad } \\
\text { after COVID-19 pandemic? }{ }^{+}\end{array}$} \\
\hline Fear of getting infected & 62 & 160 & $222(55.5)$ & 0.17 & 84 \\
\hline Compromised mental health & 54 & 114 & $168(42)$ & 0.61 & 20 \\
\hline Tougher admission protocol & 88 & 227 & $315(78.8)$ & 0.02 & 99 \\
\hline Less job opportunities & 71 & 187 & $258(64.5)$ & 0.06 & 98 \\
\hline Difficult to obtain permanent residency & 103 & 231 & $334(83.5)$ & 0.93 & 5 \\
\hline Travel restrictions & 96 & 226 & $322(80.5)$ & 0.41 & 44 \\
\hline Study budget & 84 & 230 & $314(78.5)$ & 0.001 & 100 \\
\hline \multicolumn{6}{|l|}{$\begin{array}{l}\text { In your opinion, which of the following measures, if taken by the } \\
\text { foreign universities, may be useful in getting admissions? }{ }^{\uparrow}\end{array}$} \\
\hline Extended deadlines of application & 104 & 220 & $324(81)$ & 0.23 & 71 \\
\hline Ease in visa formalities & 113 & 262 & $375(93.8)$ & 0.30 & 66 \\
\hline Flexible admission criteria & 109 & 260 & $369(92.2)$ & 0.07 & 99 \\
\hline Flexible study options & 106 & 257 & $363(90.8)$ & 0.04 & 99 \\
\hline
\end{tabular}

+Multi-response items.

A significantly higher proportion of females than males responded that "increasing competition in India" was one of the reasons to study or appear for licensing exams abroad before COVID-19 (p<0.001). A significantly higher proportion of female students cited the study budget as the main deterrent for pursuing a career abroad after the COVID-19 pandemic $(\mathrm{p}=0.001)$. Concerning the measures to be taken by the foreign universities, a significantly higher number of female students opined that "flexible study options" would help them in getting admissions post-COVID-19 ( $\mathrm{p}=0.035)$ (Table 2).

Construct validity was evaluated with the variable that assessed the "reasons that had led to the decision to study or appear for licensing exams overseas before COVID-19" among students who were not sure and those who have applied or searched colleges. There were significant differences in 4 out of the seven items in this domain. However, in the domain "cons of pursuing your career abroad after COVID-19 pandemic," only the study budget showed significant difference among students who were not sure and those who have applied or searching colleges. The rest of the items were perceived similarly among students who were not sure and those who have applied or searching colleges.

The overall reliability coefficient was 0.65 , and the coefficient decreased when any of the items were deleted. The reliability coefficient for the domain "reasons that had led to the decision to study or to appear for 
licensing exams overseas before COVID-19" was 0.54 and the coefficient decreased when any item was deleted. The reliability coefficient for the domain "cons of pursuing your career abroad after COVID-19 pandemic" was 0.58 , and the coefficient decreased when any item was deleted.

\section{Discussion}

We aimed to evaluate the perception of Indian dental students in pursuing their career abroad post COVID-19 pandemic. Most students were females, which could be attributed to females choosing dentistry as a career in many dental schools in India. It can be attributed to the belief of females being able to effectively balance a personal and professional life, as the dental profession allows for a more flexible working schedule $[18]$.

Continuing education overseas may present many challenges like visa requirements, homesickness, financial constraints, and other factors. During colonial times, the trend for Indian students was to study in the UK, to a lesser extent, to other European countries and the US [19] Post-Independence. Students received support from the government.

Our results reflected that while $37.7 \%$ of students were sure about appearing for licensing exams to go abroad post COVID-19 pandemic, $40.2 \%$ of the students were uncertain about studying for licensing exams for going abroad.

For most students, better education and training opportunities were the most influential factor for higher education abroad, similar to previous reports on Indian dental students [20]. However, there were no significant differences between males and females except for "increased competition in India." Most students in our study opted to study USA, Canada, Australia, and New Zealand. It could be due to the ease of communication, lifestyle, and freedom offered by these countries [21]. On the other hand, when it came to the countries which everyone preferred the least were South Asia and the Middle East. The lack of enthusiasm in dental students for middle eastern countries could be attributed to several challenges: supportive services, restricted movement, communication, and discrimination challenges [22]. Europe, on the other hand, was the continent about which the students relatively had equal opinions. However, there were no significant differences between males and females.

The current status of the application of the students who gave the nod to move abroad in the future, $27.2 \%$ of students were looking for colleges, and only $2.3 \%$ were enrolled in their desired college. In contrast, most students (66.5\%) were not sure about the status of their application. These students' plans may have been canceled or delayed due to the unexpected lockdown of various countries resulting in the sudden suspension of classes and the halt of visa processes [23]. Nearly one-fifth of these students had their plans unchanged because some are hopeful that COVID-19 is a temporary situation.

On the one hand, living abroad seems to be rewarding and satisfactory in terms of money and lifestyle. According to several studies conducted in Vietnam and Japan, most students identify the lack of financial aid as the prime factor in not going abroad [24]. Especially in these extraordinary times, one's fear of going abroad may increase many folds due to the added drawbacks like changing countries' policies. For example, the USA has altered its rules for an H1B visa, affecting many students in the future [25]. A majority of students identified financial budget, strict admission protocols, and fewer chances of getting a permanent residency being the most critical factor for not going abroad.

We have seen significant differences between males and females concerning the perceptions of pursuing higher education. A higher number of female students were "not sure" and are still in "searching 
colleges" and were "uncertain" or "postponed" or "canceled" regarding the current plan to study abroad when compared to the males. Our study showed that more females than males perceived "increasing competition in India" as one reason to study abroad before COVID-19. Also, female students cited the study budget as the main deterrent for pursuing a career abroad. They opined that universities should allow for "flexible study options" to help them get admissions post-COVID-19. These differences could be because females may have a higher number of goals, due to which they perceive more negative outcomes than males after attaining higher job responsibilities. It may eventually conflict with their other life goals. It was also seen that females are less likely to take up high-power job responsibilities even when there was no extra effort [26].

Studies have suggested that dynamic hybrid training, which consists of traditional clinical training with online newer teaching methodologies, is the current requisite. Dental education has to cope with the COVID-19 pandemic, and institutions need to develop strategies to provide a safe dental learning environment for effective clinical training of future dental students.

\section{Conclusion}

The sudden emergence of the COVID-19 pandemic disrupted many dental students' plans to pursue higher studies from universities abroad. Overall, a substantial impact was perceived by Indian dental students concerning pursuing higher education abroad. Also, the effect was more for female students when compared to male students.

\section{Authors' Contributions}

\begin{tabular}{|c|c|c|}
\hline NS & (D) https://orcid.org/0000-0001-6414-5741 & $\begin{array}{l}\text { Conceptualization, Methodology, Investigation, Writing - Original Draft and Project } \\
\text { Administration. }\end{array}$ \\
\hline SG & (iD) https://orcid.org/0000-0002-0940-2191 & Conceptualization, Methodology, Investigation and Writing - Original Draft \\
\hline KCP & (D) https://orcid.org/0000-0002-5462-5677 & $\begin{array}{l}\text { Conceptualization, Methodology, Formal Analysis, Investigation, Writing - Original Draft, } \\
\text { Writing - Review and Editing and Supervision. }\end{array}$ \\
\hline AT & (iD) https://orcid.org/0000-0002-6473-8093 & Conceptualization, Methodology, Data Curation, Writing - Review and Editing and Supervision. \\
\hline
\end{tabular}

\section{Financial Support}

None.

\section{Conflict of Interest}

The authors declare no conflicts of interest.

\section{Data Availability}

The data used to support the findings of this study can be made available upon request to the corresponding author.

\section{Acknowledgment}

The authors wish to thank everyone who participated in this study.

\section{References}

[1] Dental Council of India. Available from: https://dciindia.gov.in/. [Accesssed on September 13, 2020].

[2] Vundavalli S. Dental manpower planning in India: current scenario and future projections for the year 2020. Int Dent J 2014; 64(2):62-7. https://doi.org/10.1111/idj.12063

[3] Nagarajan R. Dentists or doctors, can just adding to numbers work?. Times of India. 2019. Available from: https://timesofindia.indiatimes.com/india/dentists-or-doctors-can-just-adding-to-numberswork/articleshow/68979529.cms [Accessed on September 13, 2020]. 
[4] Folayan MO, Sofola OO, Khami MR, Esan AO, Popoola BO, Orenuga OO, et al. Study motives, career choices and interest in paediatric dentistry among final year dental students in Nigeria. BMC Med Educ 2014; 14:130. https://doi.org/10.1186/1472-6920-14-130

[5] Halawany HS, Binassfour AS, AlHassan WK, Alhejaily RA, Al Maflehi N, Jacob V, et al. Dental specialty, career preferences and their influencing factors among final year dental students in Saudi Arabia. Saudi Dent J 2017; 29(1):15-23. https://doi.org/10.1016/j.sdentj.2016.12.001

[6] Aditya S. Motivations and future aspirations of dental interns: A cross-sectional study. SRM J Res Dent Sci 2013; 4(3):114-8. https://doi.org/10.4103/0976-433x.121635

[7] Fita S, Alshuraim F, Almulhim A, Alhumaid J, Alhareky M, Nazir M. Possible future career challenges and associated factors among dental students and interns. Int J Dent 2020; 2020:9730125. https://doi.org/10.1155/2020/9730125

[8] Yadav S, Rawal G. The current status of dental graduates in India. Pan Afr Med J 2016; $23: 22$. https://doi.org/10.11604/pamj.2016.23.22.7381

[9] Stroud AH. Should I stay or should I go?: Factors impacting the decision to study abroad among students who have expressed intent. [Doctoral Dissertation]. University of Massachusetts Amherst; 2015.

[10] Phelan AL, Katz R, Gostin LO. The novel Coronavirus originating in Wuhan, China. JAMA 2020; 323(8):709-10. https://doi.org/10.1001/jama.2020.1097

[11] Sarkodie SA, Owusu PA. Impact of COVID-19 pandemic on waste management. Environ Dev Sustain 2020; $10: 207$. https://doi.org/10.1007/s10668-020-00956-y

[12] Singh KT, Mishra G, Shukla AK, Behera S, Tiwari AK, Panigrahi S, et al. Preparedness among dental professionals towards COVID-19 in India. Pan Afr Med J 2020; 36:1-7. https://doi.org/10.11604/pamj.2020.36.108.23694

[13] Bhumireddy J, Mallineni SK, Nuvvula S. Challenges and possible solutions in dental practice during and post COVID-19. Environ Sci Pollut Res 2020; 28(2):1275-7. https://doi.org/10.1007/s11356-020-10983-x

[14] Peres KG, Reher P, de Castro RD, Vieira AR. Covid-19-related challenges in dental education: Experiences from Brazil, the USA, and Australia. Pesqui Bras Odontopediatria Clin Integr 2020; 20(supp1):e0131. https://doi.org/10.1590/pboci.2020.130

[15] Iyer P, Aziz K, Ojcius DM. Impact of COVID-19 on dental education in the United States. J Dent Educ 2020; 84(6):718-22. https://doi.org/10.1002/jdd.12163

[16] Choi B, Jegatheeswaran L, Minocha A, Alhilani M, Nakhoul M, Mutengesa E. The impact of the COVID-19 pandemic on final year medical students in the United Kingdom: A national survey. BMC Med Educ 2020; $20: 206$. https://doi.org/10.1186/s12909-020-02117-1

[17] Hung M, Licari FW, Hon ES, Lauren E, Su S, Birmingham WC, et al. In an era of uncertainty: Impact of COVID-19 on dental education. J Dent Educ 202 1; 85(2):148-56. https://doi.org/10.1002/jdd.12404

[18] Saadi D. Report: The Shifting of Gender in Dentistry. Inside Dentistry. 2008. Available from: https://www.aegisdentalnetwork.com/id/2008/02/report-the-shifting-of-gender-in-dentistry. [Accessed on September 13, 2020].

[19] Confederation of Indian Industry. Trends in internationalization of Higher Education in India. 2014. Available from: https://ciihighereducation.in/pdf/reports-feed/Trends in Inter Higher Education.pdf. [Accessed on September 13, 2020].

[20] Prabeerkumar S. Dental graduates look towards foreign shores. The Times of India. 2016. Available from: https://timesofindia.indiatimes.com/city/hyderabad/Dental-graduates-look-towards-foreignshores/articleshow/54097262.cms. [Accessed on September 13, 2020].

[21] Balasubramanian M, Brennan DS, Spencer AJ, Short SD. "Newness-struggle-success" continuum: A qualitative examination of the cultural adaptation process experienced by overseas-qualified dentists in Australia. Aust Heal Rev 2016; 4O(2):168-73. https://doi.org/10.1071/AH15040

[22] Zawawi AN, Al-Rashed AM. The experiences of foreign doctors in Saudi Arabia: A qualitative study of the challenges and retention motives. Heliyon 2020; 6(8):e03901. https://doi.org/10.1016/j.heliyon.2020.e03901

[23] Study abroad dreams shattered or delayed due to COVID-19, students look for plan B n.d. Available from: https://economictimes.indiatimes.com/industry/services/education/study-abroad-dreams-shattered-or-delayed-dueto-covid-19-students-look-for-plan-b/articleshow/74990680.cms?utm_source\%3Dwhatsapp_web\%26utm_ medium\%3Dsocial\%26utm_campaign\%3Dsocialsharebuttons. [Accessed on September 13, 2020].

[24] Yamashita D, Watari H. Inward-Looking Japanese Young People: A Case on the Second Year Engineering Students of a Rural National University. In: 2014 International Conference on Education Reform and Modern Management (ERMM-14). Atlantis Press, 2014. p. 121-124.

[25] Ray A. US student visa rule changed in the wake of COVID-19. Mint. 2020. Available from: https://www.livemint.com/news/world/us-student-visa-rule-changed-in-the-wake-of-covid-19-key-points-to-know11595774883224.html. [Accessed on September 13, 2020].

[26] Gino F, Wilmuth CA, Brooks AW. Compared to men, women view professional advancement as equally attainable, but less desirable. Proc Natl Acad Sci 2015; 112(40):12354-9. https://doi.org/10.1073/pnas.1502567112 